\title{
Serum concentration of interleukin 15, interleukin 2 receptor and TNF receptor in patients with polymyositis and dermatomyositis: correlation to disease activity
}

\author{
Pawel Mielnik $\cdot$ Hanna Chwalinska-Sadowska $\cdot$ \\ Ewa Wiesik-Szewczyk • Wlodzimierz Maslinski • \\ Marzena Olesinska
}

Received: 7 July 2010/Accepted: 14 November 2010/Published online: 4 December 2010

(C) The Author(s) 2010. This article is published with open access at Springerlink.com

\begin{abstract}
Cytokines are implied in polymyositis/dermatomyositis (PM/DM) pathogenesis. Our aim was to evaluate the serum levels of interleukin-15 (IL-15), soluble receptors for IL-2 (sIL-2R) and TNF-alpha type 1 receptor (sTNF-R1) in PM/DM patients and their relation to disease activity and clinical symptoms. Thirty-eight patients who met definite or probable criteria of Bohan and Peter for $\mathrm{DM} / \mathrm{PM}$ were included into the study. Results in patients with active (41 observations) and inactive disease (24 observations) were compared with control (15 subjects). The median level of IL-15 was $47.6 \pm 170 \mathrm{pg} / \mathrm{ml}$ in active patients, $25.15 \pm 240 \mathrm{pg} / \mathrm{ml}$ in inactive and $28.5 \pm$ $28.89 \mathrm{pg} / \mathrm{ml}$ in controls. We demonstrated significant differences between active patients and controls in levels of IL-15 (0.016, 95\%CI 1.39-57.1). The median level of sIL$2 \mathrm{R}$ was $314 \pm 388,235.3 \pm 269$ and $144.3 \pm 152.9 \mathrm{pg} /$ $\mathrm{ml}$, and the median level of sTNF-R1 was $350 \pm 388$; $294.7 \pm 204.7 ; 209.5 \pm 105.9 \mathrm{pg} / \mathrm{ml}$ in active, inactive and control subjects, respectively. There were significantly higher serum levels of these cytokines in active patients than in control subjects (for sIL-2R $P=0.05$, CI95\% 0.4-331; and sTNF-R1 $P=0.031$, CI95\% 15.1-321.5). The interleukin levels did not differ between inactive patients and controls. Elevation of IL-15, sIL2-R and sTNF-R1 in active patients provides preliminary evidence
\end{abstract}

P. Mielnik $(\bowtie) \cdot$ H. Chwalinska-Sadowska .

E. Wiesik-Szewczyk · M. Olesinska

Department of Connective Tissue Diseases,

Institute of Rheumatology, Spartanska 1,

Warsaw, Poland

e-mail: mielnik.p@gmail.com

W. Maslinski

Department of Pathophysiology and Immunology,

Institute of Rheumatology, Warsaw, Poland for the activation of inflammatory response during PM/DM flares. Further studies may be needed to explain the mechanisms driving these diseases.

Keywords Dermatomyositis - Polymyositis . Interleukin-15 - Disease activity

\section{Introduction}

Interleukin-15 (IL-15) is a proinflammatory cytokine with pleiotropic activity. It stimulates the proliferation and activation of $\mathrm{T}$ cells, macrophages, CD5 memory lymphocytes and cytotoxic CD8 lymphocytes, proliferation of myoblasts, endothelial cells and many others [1]. The IL15-specific receptor is composed of 3 subunits: alpha, beta and gamma. The latter is shared with IL-2 and other cytokines (IL-4, IL-7, IL-9 and IL-21), which explains their similar effects. IL-15 seems to have the widest activity spectrum of the whole IL-2 family. Both, IL-15 receptors and IL-15 mRNA, were found in many non-immunological tissues and cells (placenta, muscle, kidney, heart, fibroblasts and myoblasts) [1].

Sugiura et al. published data that suggested that IL-15 plays a role in PM/DM pathogenesis. Increased production of biologically active IL-15 was found in myoblasts collected from patients with DM and PM [2]. Moreover, increased serum cytokine level was found in $11 \mathrm{PM} / \mathrm{DM}$ patients; however, no specific clinical data were given [3]. Our aim was to assess IL-15 levels in sera of PM/DM patients in comparison with healthy controls.

At present, laboratory parameters related to disease activity in PM/DM are still lacking. Potentially, serum levels of IL-15 could help to quantify this activity. We therefore determined the serum levels of IL-15 in DM/PM 
patients in relation to disease activity. We also analysed the serum levels of soluble TNF-alpha type 1 receptor (sTNFR1) and soluble interleukin-2 receptor (sIL2-R) in order to compare our group with data from earlier studies [4-6].

\section{Materials and methods}

Thirty-eight patients with definite or probable PM/DM, according to criteria by Bohan and Peter, were included in the study [7]. At study entry, we excluded all patients with any inflammatory myopathy other than PM/DM or other inflammatory disorder. Study procedures were performed twice: at study entry (first time-point) and 6-9 months later (second time-point). Fifteen healthy subjects, matched for age and sex, were the control group. At both time-points, all patients were subjected to physical examination and routine blood tests. Serum autoantibody assays were performed at study entry. Other examinations were performed if clinically indicated. Serum IL-15, sTNF-R1 and sIL2-R were assessed using specific ELISAs. For IL-15, we used antibodies produced by $R \& D$ System Inc. and standard IL15 from Genzyme Corporation. We used commercial kits by $B D$ Sciences for sTNF-R1 and kits by BioSource Company for IL-2R. The sera were collected in the morning between 7 and 9 a.m., in the fasting state. Immediately after being centrifuged, the sera were frozen at $-70^{\circ} \mathrm{C}$.

Depending on disease activity, patients were allocated to one of two groups, termed "active" and "remission", respectively. Patients were deemed "active" in the presence of at least 1 of the following:

1. Active myositis. Judgment was based on clinical status and preformed by one investigator (PM). New, worsening or stable muscle weakness, with or without myalgia, with elevation of muscle enzymes were defined as active myositis.

2. Active interstitial lung disease (ILD) defined as radiologically confirmed interstitial changes (HRCT) with the presence of "ground glass" opacities and/or significant worsening of DLCO since the last test.

3. Active skin lesions defined as the presence of at least 1 of the following features: skin ulceration, erythroderma, erythema accompanied by vesiculobullous or erosive lesions or necrosis, panniculitis, erythematous rashes without secondary lesions, heliotrope rash, Gottron's papules or sign, periungual capillary changes, alopecia or mechanic's hands. Listed symptoms were assessed as active if they failed to improve during the 4-week preceding examination.

4. Other clinically relevant features that were judged as connected to disease activity. These included clinically active polyarthritis, dysphagia, myocarditis, pericarditis, gastrointestinal ulceration and fever.

IL-15, sTNF-R1 and sIL-2 levels were compared between the two patient groups as well as between "active" patients and controls and between "remission" patients and controls. In patients examined twice, we assessed the change in cytokine levels and their relationship with the clinical status and laboratory parameters.

The statistical significance of differences in IL-15, sTNF-R1 and sIL2-R levels between patient groups and control subjects was analysed using the Student's $t$-test when the group's data had normal distribution and similar variance or the Wilcoxon test when these conditions were not met. Multiple regression analysis was performed to identify potential correlation between cytokine levels and clinical data.

The study was approved by the local Ethical Committee. All subjects provided informed consent before any study procedure.

\section{Results}

There were no significant differences in demographic status between the patient and control groups (Table 1). Clinical features are gathered in Table 2.

The most common symptom was muscle weakness with the elevation of CK. ILD was the most frequent internal organ involvement. Antinuclear antibodies (ANA) were positive in 29 patients (55.6\%), anti-Jo-1 antibodies in 9 $(23.6 \%)$ at the first time-point of study. Before study entry, $65.7 \%$ of patients were medically treated, glucocorticosteroids (GCS) being most frequently used medication (65.7\%). Median GCS dose was $11 \mathrm{mg}$ and treatment median time before the first study time-point was 2.5 months. At the first time-point, 6 patients were treated with cyclophosphamide (CYC), 5 with azathioprine (AZA) and 3 with methotrexate (MTX). At the second evaluation, almost all patients were treated (96.8\%) again mainly with GCS $(96.8 \%$, median dose $15 \mathrm{mg}$, median treatment duration 28 months). Other treatments included MTX (7\%), cyclosporin A (CsA, 22\%), CYC (19\%) and chloroquine $(7 \%)$.

Table 1 Demographic data of the patient and control groups

\begin{tabular}{llll}
\hline & Patients & Controls & $P$ \\
\hline Gender (F/M) & $21 / 17$ & $8 / 7$ & NS \\
Age & $53 \pm 13.5$ & $44 \pm 14.8$ & NS \\
Disease duration (months) & $12 \pm 60$ & NA & NA \\
\hline
\end{tabular}

$P$ statistics for the comparison between patients and controls

$N S$ non-significant, $N A$ not applicable 
Table 2 Clinical features in examined group

\begin{tabular}{lcc}
\hline Study point & 1 st $(n=38)$ & 2nd $(n=27)$ \\
\hline Muscle weakness & $30(78.8 \%)$ & $16(59.2 \%)$ \\
Myalgia & $11(28.9 \%)$ & $1(3.7 \%)$ \\
Fever & $4(10.5 \%)$ & 0 \\
ILD & $16(42.1 \%)$ & $9(33.3 \%)$ \\
Dysphagia & $5(13.1 \%)$ & $4(14.8 \%)$ \\
Dysphonia & $4(10.5 \%)$ & 0 \\
Cardiac involvement & $2(5.3 \%)$ & 0 \\
Arthritis & $8(21 \%)$ & $1(3.7 \%)$ \\
Gottron's sign & $9(23.7 \%)$ & $4(14.8 \%)$ \\
Heliotrope & $12(31.6 \%)$ & $8(29.6 \%)$ \\
Periungual changes & $9(23.7 \%)$ & $1(3.7 \%)$ \\
Skin ulcers & $2(5.3 \%)$ & $1(3.7 \%)$ \\
Other erythemas & $8(21.1 \%)$ & $7(25.9 \%)$ \\
Mechanic's hands & $4(10.5 \%)$ & $2(7.4 \%)$ \\
Oedema & $1(2.6 \%)$ & 0 \\
Livedo reticularis & $4(10.5 \%)$ & $3(11.1 \%)$ \\
Raynaud's phenomenon & $4(10.5 \%)$ & $3(11.1 \%)$ \\
Active skin changes & $19(50 \%)$ & $17(62.9 \%)$ \\
Active subjects & $30(78.9 \%)$ & $11(40.7 \%)$ \\
\hline
\end{tabular}

Number of patients with present feature

Although we assumed that the other forms of inflammatory myopathies were exclusionary, three patients had been diagnosed with malignant tumours during the study and eventually diagnosed with cancer-induced DM. Four patients died during the observation: two due to cancer, one due to cardiomyositis related to PM and one due to heart and lung failure caused by ILD.

Overall, we assessed 27 patients twice and 11 once. The absence of the second assessment resulted from the following causes: death in four cases; loss from followup in seven cases ( 2 moved to another region of the country, 5 could not come within projected timelines). In our group, 30 patients $(78.9 \%)$ were assessed as active at the first time-point and $11(40.7 \%)$ at the second. Together, we made 41 assessments in active disease and 24 in inactive. The proportion of patients with PM to patients with DM in both groups was similar (45\% vs. $50 \%, \mathrm{NS})$.

IL-15 levels were significantly higher in the whole patient group in comparison with the control group at the first time-point of the study (Table 3). Median values were $45 \pm 188.02 \mathrm{pg} / \mathrm{ml}$ versus $28.5 \pm 28.89 \mathrm{pg} / \mathrm{ml}$ in control $(P=0.038)$. Median for summarized results in patients' group was $43.8 \pm 205.14$ and was significantly higher than in control $(P=0.05,95 \%$ CI 20-126).

The median level of IL-15 was twice as high in active comparing to inactive patients, but difference was not statistically significant. The median level in active group
Table 3 IL15, sIL2-R and sTNF-R1 levels in PM/DM patients (in the first and second study time-point) and in control group

\begin{tabular}{lcl}
\hline & Median $(\mathrm{pg} / \mathrm{ml})$ & $P$ versus control/95\% CI \\
\hline IL-15 at 1st point & $45 \pm 188.02$ & $0.038 / 17.8-47.4$ \\
IL-15 2nd point & $28.53 \pm 222.76$ & $0.15 / 0.017-48.7$ \\
IL-15 control & $28.5 \pm 28.89$ & NA \\
sIL-2R at 1st point & $317.2 \pm 335.8$ & $0.027 / 4.9-345$ \\
sIL-2R 2nd point & $159.9 \pm 563.8$ & $0.4 / 0.001-231$ \\
sIL-2R control & $144.3 \pm 152.9$ & NA \\
sTNF-R1 at 1st point & $328.8 \pm 647.7$ & $0.067 /(-11)-286.5$ \\
sTNF-R1 2nd point & $367.9 \pm 724.0$ & $0.041 / 9.81-213.9$ \\
sTNF-R1 control & $205.9 \pm 629.6$ & NA
\end{tabular}

Median level and standard deviation. $P$ and $95 \% \mathrm{CI}$ between patients and controls

was significantly higher $(P=0.016)$ than in control group (Table 4).

We identified no specific clinical feature related to higher IL-15 levels. Previous treatment also had no impact on IL-15 levels.

At study entry, sIL2-R concentration was significantly higher $(P=0.027)$ in the patient group in comparison with controls. This was not found at the second time-point.

The sTNF-R1 and sIL2-R levels, as well as IL-15 levels, were significantly higher in active subjects than in controls $(P<0.05, P=0.031, P=0.016$, respectively; Table 4). The sTNF-R1 median was higher in patients with malignancies $(1,017 \mathrm{pg} / \mathrm{ml})$ than in other patients $(327 \mathrm{pg} / \mathrm{ml})$ and significantly higher than in the control group $(P=0.04)$. The levels of sTNF-R1 and sIL2-R were not related to any clinical symptoms, laboratory results or treatment.

Median levels of IL-15, sIL2-R and sTNF-R1 in patients who died were not significantly different from whole group, active patients, non-active patients or controls and were $32.1,266.7$ and $417.3 \mathrm{pg} / \mathrm{l}$, respectively.

\section{Discussion}

The role of IL-15 in the pathogenesis of inflammatory, autoimmune disease like rheumatoid arthritis has been demonstrated, but data explaining the role of IL-15 in the pathogenesis of PM/DM are limited [8-10].

IL-15 seems to be the ideal candidate for the factor sustaining the inflammation in these rare diseases, as it is not only produced by myoblasts, but also its receptor has been found in muscle tissue [1]. The increased synthesis of IL-15 by myoblasts isolated from PM/DM patients, but not from healthy controls, was shown by Siagura et al. [2].

In the present report, we confirm the existence of higher levels of IL-15 in PM/DM patients compared to healthy controls as was previously reported by Suzuki et al. [3] 
Table 4 IL15, sIL2-R and sTNF-R1 levels in active (1), inactive (2) patients and control group (3)

\begin{tabular}{llllcc}
\hline & Active & Inactive & Control & $P$ & $\begin{array}{l}P(95 \% \text { CI }) \\
1 \text { versus 3 }\end{array}$ \\
\hline IL-15 & 2 & 3 & 1 versus 2 & N & Nersus 3 \\
sIL-2R & $47.6 \pm 170$ & $25.15 \pm 240$ & $28.5 \pm 28.89$ & NS \\
sTNF-R1 & $314 \pm 388$ & $235.3 \pm 269$ & $144.3 \pm 152.9$ & NS & $0.05(1.39-57.1)$ \\
\hline
\end{tabular}

$P$ statistic and $95 \% \mathrm{CI}$ between active patients and inactive patients; active patients and controls, inactive patients and controls

Moreover, we found a correlation between disease activity and IL-15 serum concentration. Not all measured parameters achieved statistical significance, possibly due to the relatively small number of patients included in our study. Suzuki et al. found higher levels of IL-15 in patients with various inflammatory connective tissue diseases and ILD [3]. We did not demonstrate a similar phenomenon in our group, but our study selected only PM/DM patients with the possible domination of muscle IL-15 production. Our results add to previous observations and give further evidence in favour of a stimulating role of IL-15 in these diseases.

We noted higher levels of sTNF-R1 and sIL2-R in the patients in active disease. High sIL2-R levels have been found in many inflammatory and neoplasmatic conditions, often correlating with disease activity and determining prognosis [4, 10-13]. We demonstrated a correlation between sIL2-R levels and disease activity, but not with any specific clinical parameter. Samsonov et al. [4] failed to notice any correlation between myositis activity and serum concentrations of sIL2-R; however, they did find such an association with ESR.

Our results of sTNF-R1 levels are consistent with previous reports $[5,6]$. Other authors found correlation with disease activity not only for sTNF-R1 but also for sTNF-R2 [6]. Extremely high levels of the receptor found in subjects with neoplasm-induced DM are interesting but due to the small number of patients and possible biases, no firm conclusions can be drawn. However, since high levels of sTNF-R1 were observed in cancer patients without inflammatory myopathies, it is not clear whether this parameter can be used as a differentiating factor between primary DM and cancer-induced DM [14-18].

\section{Conclusion}

High concentration of IL-15 as well as sIL2-R and sTNF$\mathrm{R} 1$ in active patients with $\mathrm{DM} / \mathrm{PM}$ provides additional evidence for a broad activation of inflammatory response. Further studies are needed to explain the mechanisms driving these diseases. High level sTNF-R1 in cases of neoplasm-induced $\mathrm{PM} / \mathrm{DM}$ requires confirmation in the future studies.

Acknowledgment This study was financed with a grant from the Ministry of Science and Higher Education, Republic of Poland. Grant 2P05B07628.

Open Access This article is distributed under the terms of the Creative Commons Attribution Noncommercial License which permits any noncommercial use, distribution, and reproduction in any medium, provided the original author(s) and source are credited.

\section{References}

1. Fehniger TA, Caligiuri MA (2001) Interleukin 15: biology and relevance to human disease. Blood 97:14-32

2. Sugiura T, Harigai M, Kawaguchi Y, Takagi K, Fukasawa C, Ohsako-Higami S et al (2002) N.Increased IL-15 production of muscle cells in polymyositis and dermatomyositis. Int Immunol 14:917-924

3. Suzuki J, Morimoto S, Amano H, Tokano Y, Takasaki Y, Hashimoto H (2001) Serum levels of interleukin 15 in patients with rheumatic diseases. J Rheumatol 28:2389-2391

4. Elkayam O, Yaron I, Shirazi I, Yaron M, Caspi D (2000) Serum levels of IL-10, IL-6, IL-1ra, and sIL-2R in patients with psoriatic arthritis. Rheumatol Int 19:101-105

5. Chrobak L, Podzimek K, Pliskova L, Kerekes Z, Zak P, Voglova J et al (1996) Serum soluble IL-2 receptor as a reliable and noninvasive marker of disease activity in patients with hairy cell leukemia. Neoplasma 43:321-325

6. Samsonov MY, Nassonov EL, Tilz GP, Geht BM, Demel U, Gurkina GT et al (1997) Elevated serum levels of neopterin in adult patients with polymyositis/dermatomyositis. Br J Rheumatol 36:656-660

7. Bohan A, Peter JB (1975) Polymyositis and dermatomyositis (first of two parts). N Engl J Med 292:344-347

8. Kurowska M, Rudnicka W, Kontny E, Janicka I, Chorazy M, Kowalczewski J et al (2002) Fibroblast-like synoviocytes from rheumatoid arthritis patients express functional IL-15 receptor complex: endogenous IL-15 in autocrine fashion enhances cell proliferation and expression of $\mathrm{Bcl}-\mathrm{x}(\mathrm{L})$ and $\mathrm{Bcl}-2$. J Immunol 169:1760-1767

9. Liew FY, McInnes IB (2002) Role of interleukin 15 and interleukin 18 in inflammatory response. Ann Rheum Dis 61(S2):100-102

10. Baslund B, Tvede N, Danneskiold-Samsoe B, Larsson P, Panayi G, Petersen J et al (2005) Targeting interleukin-15 in patients with rheumatoid arthritis: a proof-of-concept study. Arthritis Rheum 52:2686-2692 
11. Horak P, Hermanova Z, Ordeltova M, Faltynek L, Kusa L, Budikova $M$ et al (2004) Neopterin and a soluble interleukin-2 receptor in patients with systemic lupus erythematodes. Vnitr Lek 50:422-427

12. Franczuk A, Szepietowski JC, Noworolska A (2004) Serum concentrations of interleukin-2 soluble receptor (IL-2 sR) in patients with vitiligo: relationship with type and extent of the disease. Acta Dermatovenerol Croat 12:71-76

13. Fujii T, Nojima T, Yasuoka H, Satoh S, Nakamura K, Kuwana M et al (2001) Cytokine and immunogenetic profiles in Japanese patients with adult Still's disease. Association with chronic articular disease. Rheumatology (Oxford) 40:1398-1404

14. Shimizu T, Tomita Y, Son K, Nishinarita S, Sawada S, Horie T (2000) Elevation of serum soluble tumour necrosis factor receptors in patients with polymyositis and dermatomyositis. Clin Rheumatol 19:352-359
15. Goto N, Tsurumi H, Takemura M, Hara T, Sawada M, Kasahara $S$ et al (2006) Serum-soluble tumor necrosis factor receptor 2 (sTNF-R2) level determines clinical outcome in patients with aggressive non-Hodgkin's lymphoma. Eur J Haematol $77: 217-225$

16. Viac J, Vincent C, Palacio S, Schmitt D, Claudy A (1996) Tumour necrosis factor (TNF) soluble receptors in malignant melanoma: correlation with soluble ICAM-1 levels. Eur J Cancer 32A:447-449

17. Holzer G, Pfandlsteiner T, Blahovec H, Trieb K, Kotz R (2003) Serum levels of TNF-beta and sTNF-R in patients with malignant bone tumors. Anticancer Res 23:3057-3059

18. Tesarova P, Kvasnicka J, Umlaufova A, Homolkova H, Jirsa M, Tesar V (2000) Soluble TNF and IL-2 receptors in patients with breast cancer. Med Sci Monit 6:661-667 